$9+9402$

E7-93-356

R.N.Sagaidak, A.V.Yeremin

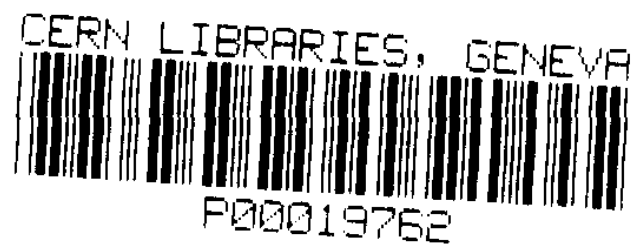

\title{
ON IONIC CHARGE DISTRIBUTIONS \\ OF HEAVY EVAPORATION RESIDUES \\ PASSING THROUGH A CARBONFOIL
}

Submitted to «Nuclear Instruments and Methods in Physics Research, Section B»

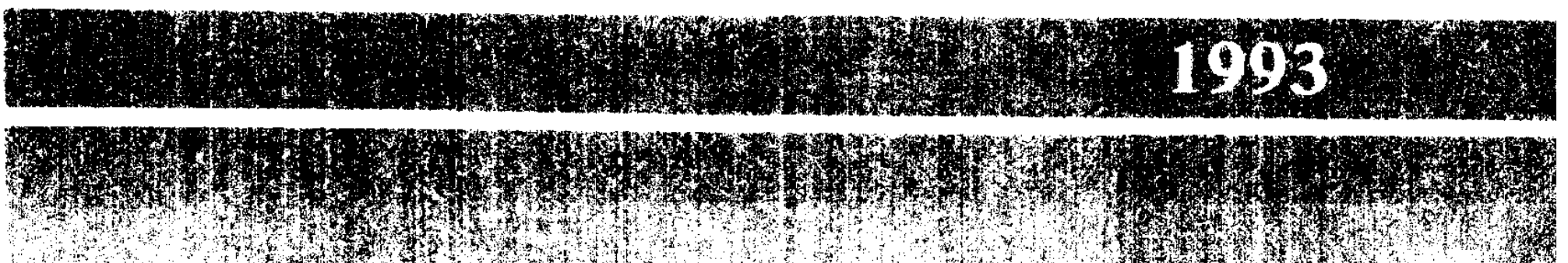




\section{-}


The knowledge of the ionic charge distributions (ICD) for heavy ion reaction products, especially for the heavy evaporation residues (ER), is important from the point of view of effective work of the kinematic recoil separators, i.e., achievement of optimum transmission (for instance see the recent review [1] and refs. therein). The ICD of the ER formed in nuclear reaction and knocked out from a target is not an equilibrated one. A possible transfer of nuclear excitation to the inner atomic shells and subsequent deexcitation of moving atoms via a cascade of Auger electrons make ICD of ER unpredictable. A carbon foil placed at a position of several centimeters downstream from a target restores the equilibrium of the ICD of ER [2].

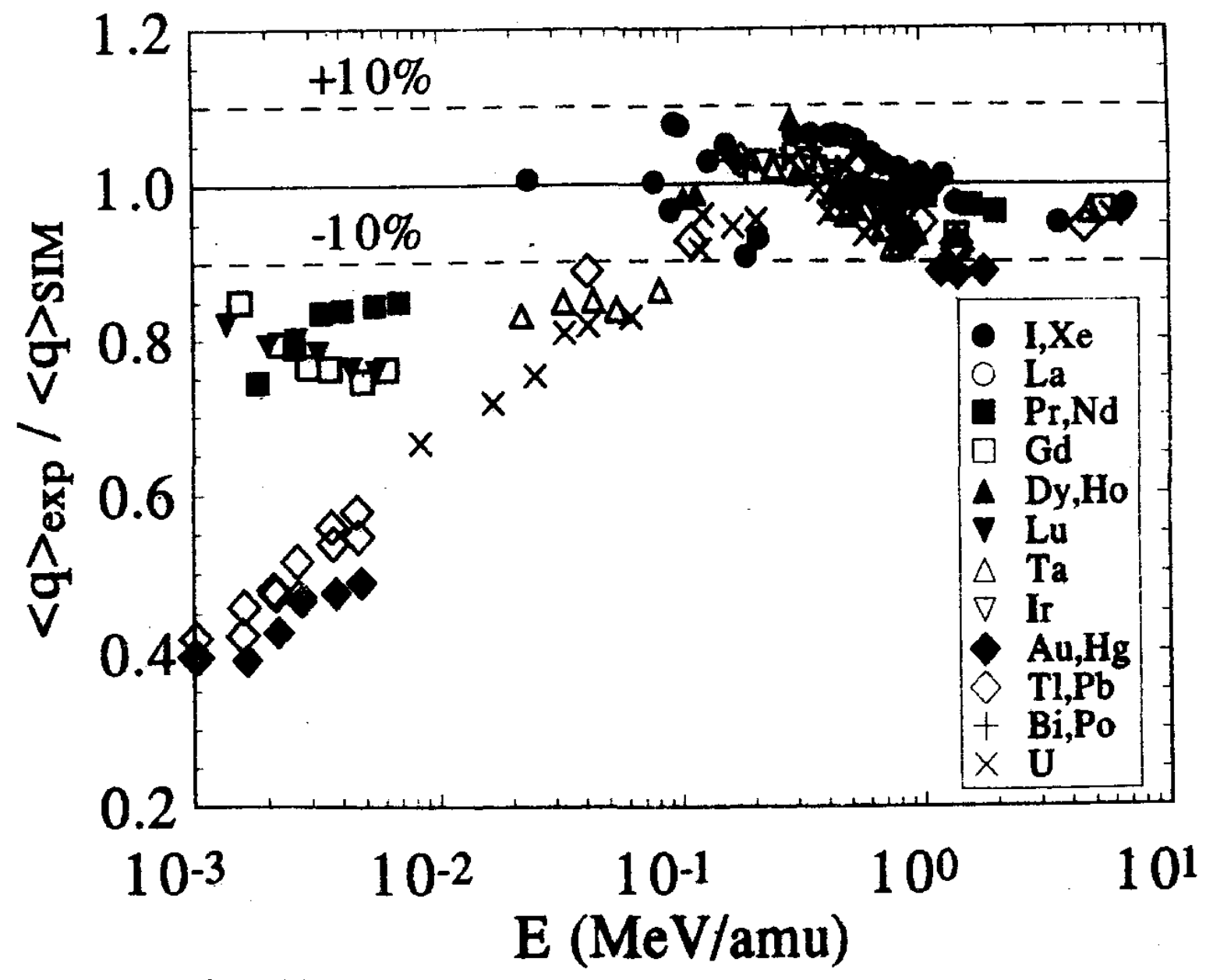

Fig.1. Comparison of experimental mean ionic charges $-\langle q\rangle_{\text {exp }}$ with the empirical predictions by Shima et al. [4] $<q\rangle_{S I M}$ (eq.(1))

Applications of the empirical systematics for the equilibrated ICD [3, 4] in ion-optical calculations for the case of specific separation systems $[5,6]$ showed significant deviations of the calculated transportation efficiencies for the ER from the experimental ones [7-9]. Evidently, this is caused by differencies of the adopted ICD from the real ones. Indeed, the data on 
the ICD for the heavy ER are poor [2]. Therefore the empirical systematics of mean charges $\langle q\rangle$ and charge distribution width $d[3,4]$ based on the data obtained for lighter ( $Z \leq 36$, mostly at $E \geq 1 \mathrm{MeV} / \mathrm{amu}$ ) heavy ions passing through a carbon foil are used for ion-optical calculations. We considered the available experimental data on ICD for $Z \geq 53$ heavy ion beams at non-relativistic energies ( $E \leq 10 \mathrm{MeV} / \mathrm{amu})$ compiled in [10-12] (see also refs.therein) and the recently obtained data [13] along with the data for ER [2]. The comparison of these data for mean charges with the predictions given by the empirical formula of Shima et al. [4] is shown in fig.1. The mean charge is expressed in this formula as

$$
\begin{aligned}
<q>_{S I M} & =Z\left[1-\exp \left(-1.25 X+0.32 X^{2}-0.11 X^{3}\right)\right], \\
X & =3.86 \sqrt{E} / Z^{0.45},
\end{aligned}
$$

where $Z$ is the ion atomic number and $E$ is the ion energy in $\mathrm{MeV} / \mathrm{amu}$.

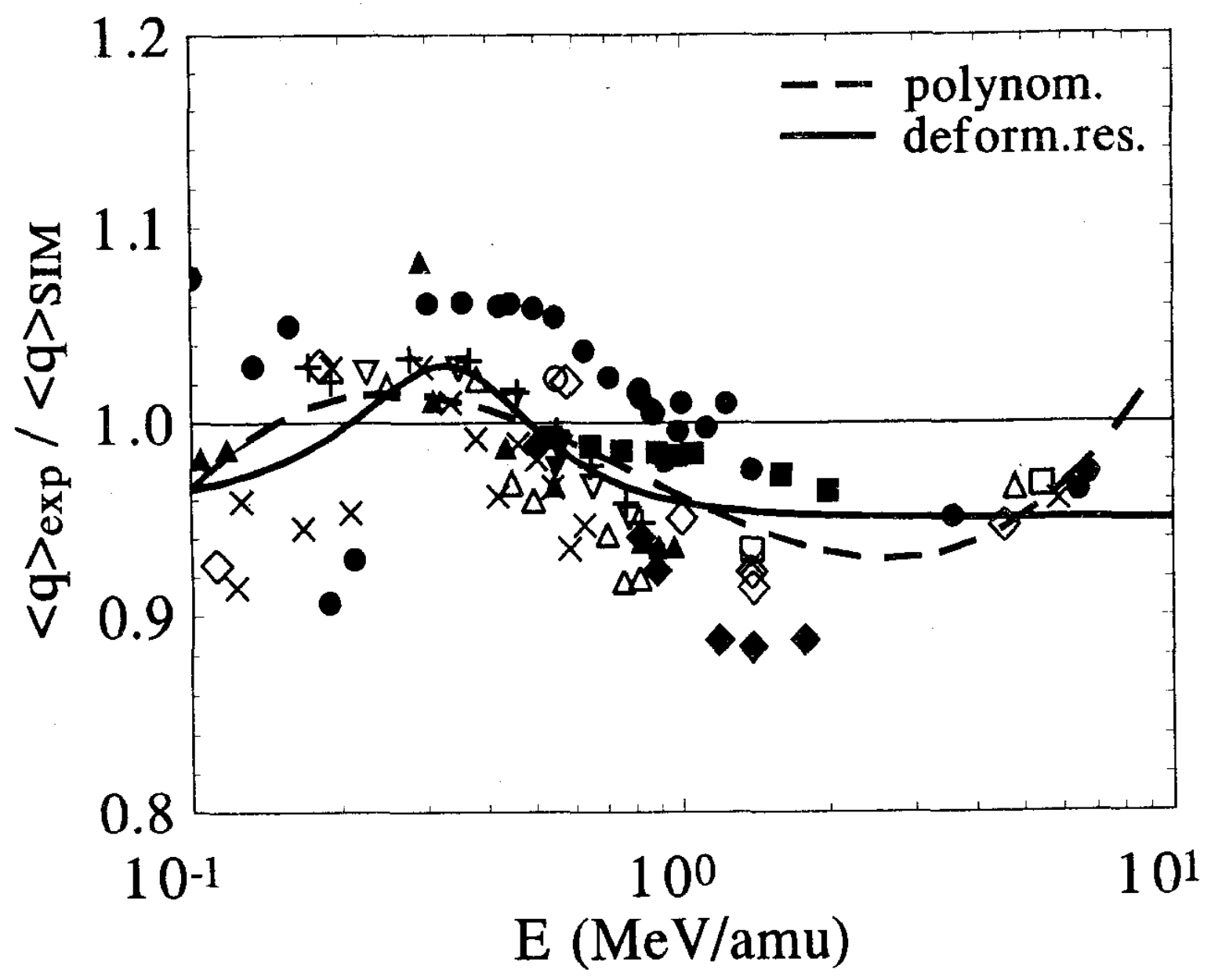

Fig.2. The same as in fig.1 except the energy region $(0.1<E<10$ $\mathrm{MeV} / \mathrm{amu}$ ). The results of least-square fit are shown: solid line -- eq.(2), dashed line - polynomial (for comparison) 
The strong deviations of the experimental data from the predictions (up to $40 \%$ ) and bad scaling with $Z$ in the energy range of our interests $(0.01<E<0.1 \mathrm{MeV} / \mathrm{amu})$ are evident from fig.1. This is observed for both systematics $[3,4]$. The similar discrepancies were obtained with others [14].

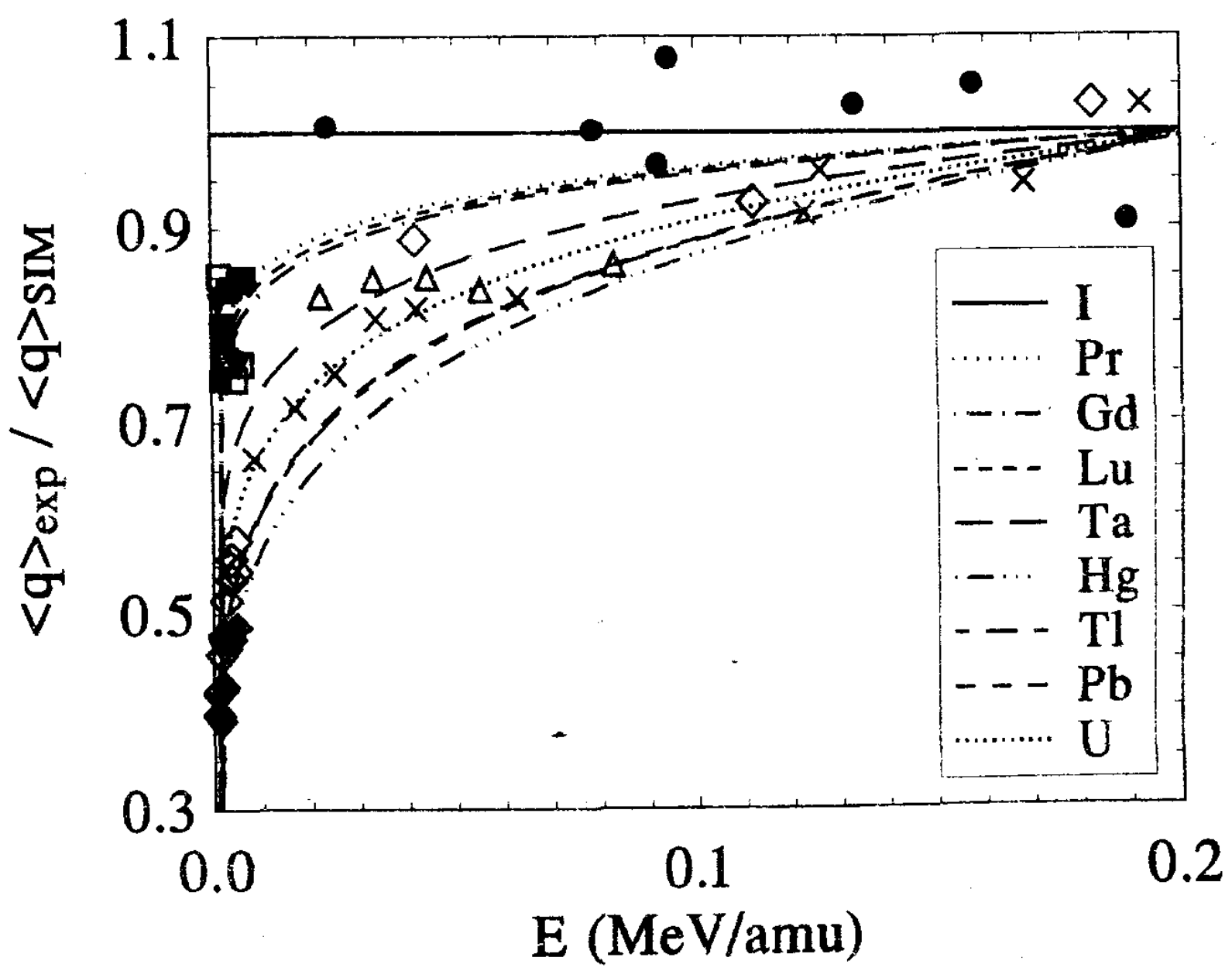

Fig.3. The same as in fig. 1 except the energy region $(0<E<0.2$ $\mathrm{MeV} / \mathrm{amu}$ ) and the energy scale (linear). The results of least-square fit using eq.(3) are shown with the different lines for ions of the different $Z$ (symbols are the same as in fig.1)

The purpose of this work is an improvement of the empirical systematics of ICD $[3,4]$ in their application to the very heavy ions. To improve the $<q>_{S I M}$-systematics we considered the ratio $R(Z, E)=<q>_{\text {exp }}$ $/<q\rangle_{S I M}$. For $E \geq 0.1 \mathrm{MeV} / \mathrm{amu} R(Z, E) \simeq f_{1}(E)$, which was approximated by a deformed resonant function:

$$
f_{1}(E)=p_{1}+\left\{p_{2} \Gamma /\left[\left(E-p_{3}\right)^{2}+\Gamma^{2}\right]\right\}, \quad \Gamma=p_{4}\left[1-\exp \left(-p_{5} E\right)\right],
$$

as it is shown in fig.2. The values of the constants $p_{1}-p_{5}$ were obtained from least-square fitting to the data at the energies $0.1 \leq E \leq$ $10 \mathrm{MeV} /$ amu (see table 1). 
Table 1. Fitted constants in eqs.(2),(3)-(6) of the correction function of eq.(7) to the mean charge evaluation given by Shima et al. [4] (eq. (1))

\begin{tabular}{cccc}
\hline \multicolumn{2}{c}{$f_{1}(E)$} & \multicolumn{2}{c}{$f_{2}(E, Z)$} \\
\hline$p_{1}$ & 0.95001 & $a_{1}$ & 1.088 \\
$p_{2}$ & 0.01488 & $a_{2}$ & $5.990 \times 10^{10}$ \\
$p_{3}$ & 0.35744 & $b_{1}$ & $5.158 \times 10^{-2}$ \\
$p_{3}$ & 0.30325 & $b_{2}$ & $3.254 \times 10^{10}$ \\
$p_{3}$ & 2.78276 & $\alpha$ & 16.993 \\
& & $\beta$ & 29.353 \\
\hline
\end{tabular}
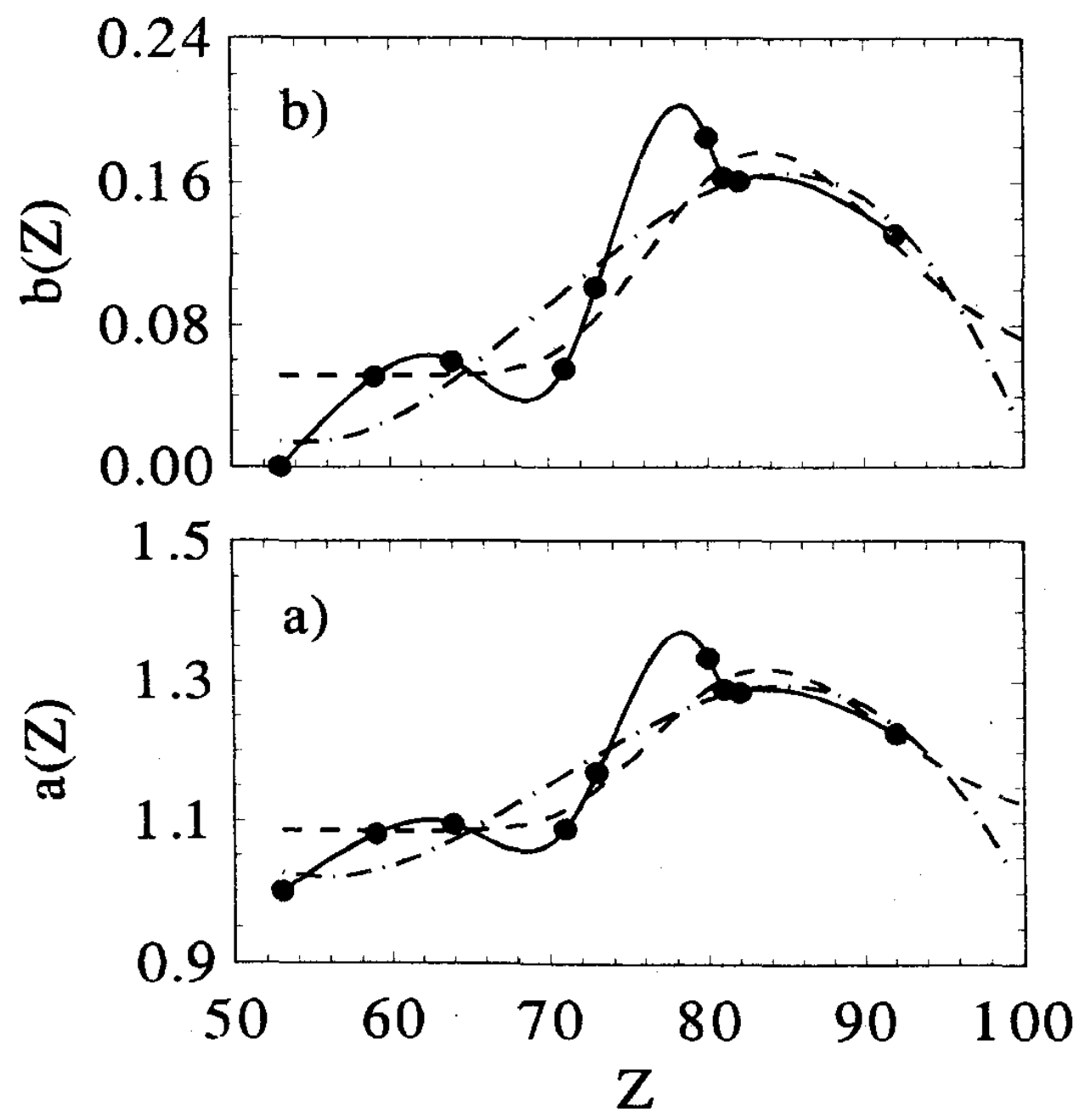

Fig.4. Changes of the parameters $a(Z)-(\mathbf{a})$ and $b(Z)-(\mathbf{b})$ vs. $Z$. Filled circles are the $a_{Z}$ and $b_{Z}$ values obtained from fit using eq.(3), solid lines are the results of a spline interpolation (see table 2), dashed lines are the results of least-square fit using eqs.(4)-(6) with constants listed in table 1. Polynomial fit is also shown for comparison (dash-dotted lines) 
For $E \leq 0.1 \mathrm{MeV} /$ amm we chose for $R(Z, E) \equiv f_{2}(Z, E)$ the form:

$$
f_{2}(Z, E)=a(Z) E^{b(Z)} .
$$

To find the parameters $a(Z)$ and $b(Z)$ we derived the values $a_{Z}$ and $b_{Z}$ by fitting the energy dependence (3) to the available data at low energies for different $Z$. The results are shown in fig. 3 . The obtained $a_{Z}, b_{Z}$ values have been fitted to the function of the form:

$$
\begin{aligned}
a(Z) & =a_{1}+a_{2} f(z), \\
b(Z) & =b_{1}+b_{2} f(z), \\
f(z) & =z^{\alpha} \exp (-\beta z), \quad z=(Z-53) / 53 .
\end{aligned}
$$
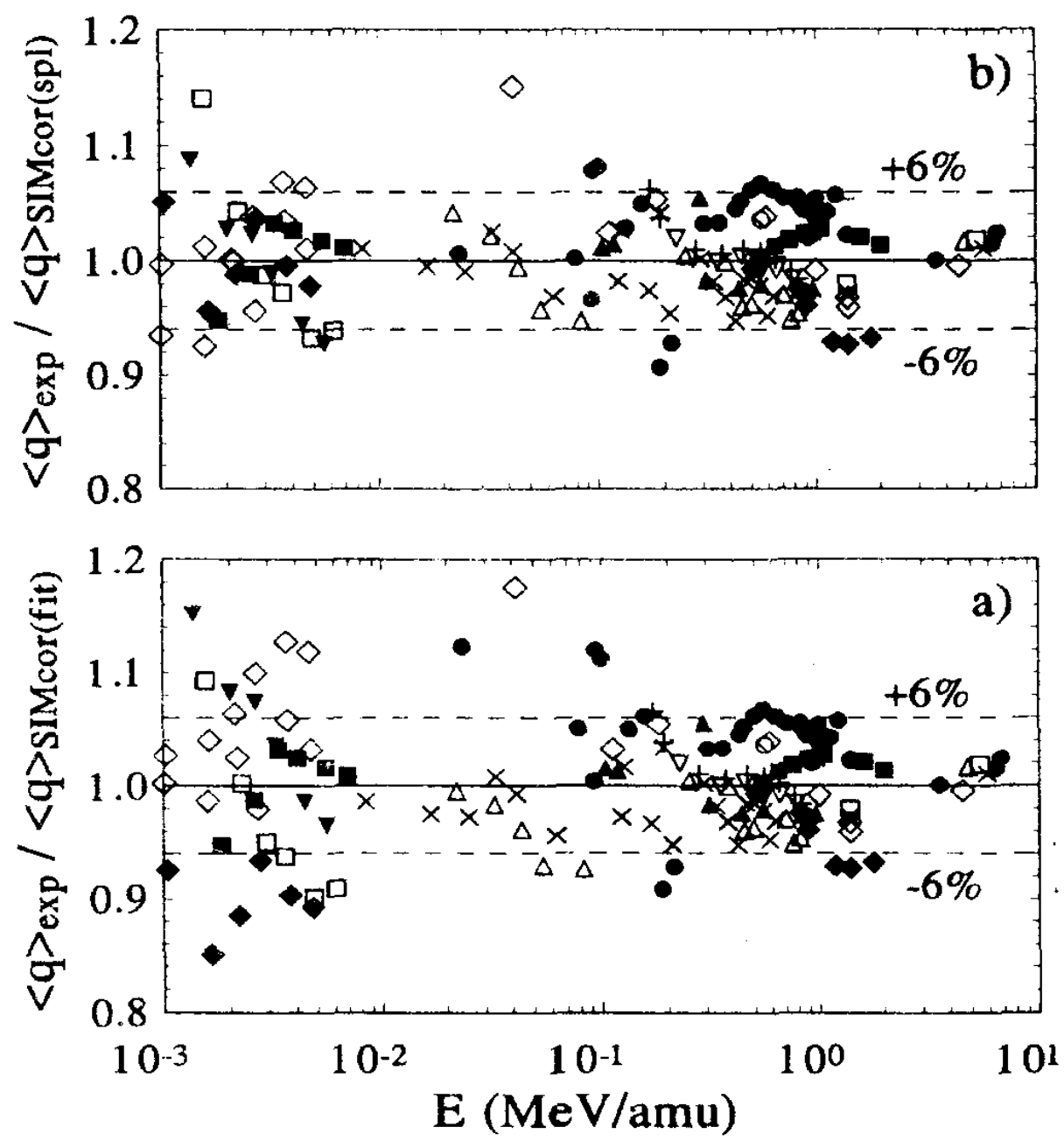

Fig.5. The same as in Fig.1 except the application of the correction function of eqs.(2) (7). Low encrgy corrections are given with the parameters $a(Z)$ and $b(z)$ of eq.(3) obtained from: a) -.- least-square fit using eqs.(4) (6) with constants in table 1 , and b) -... spline interpolation with parameters in table "2 
Results of the least-square fit are shown in fig.4. The determined from the fit constants $a_{1}, a_{2}, b_{1}, b_{2}, \alpha$ and $\beta$ are listed in table 1 . To consider the detailed behaviour of $a(Z)$ and $b(Z)$ a spline interpolation combined with a linear extrapolation for $Z>92$ was made. The obtained coefficients $a(Z)$ and $b(Z)$ are listed in table 2. The fit of the parameters of the function (3) was satisfying the condition of matching with the function (2) at $E=0.21 \mathrm{MeV} / \mathrm{amu}$, where approximate equality $f_{1}(E) \simeq$ $f_{2}(E, Z) \simeq 1$ was fulfilled (see figs.2,3 also).

Combining (2) and (3) the correction function to the formula of Shima et al. [4] could be expressed as

$$
R(E, Z)=k f_{1}(E)+(1-k) f_{2}(E, Z), \quad \text { where } \quad k= \begin{cases}1, & E \geq 0.21 \\ 0, & E<0.21\end{cases}
$$

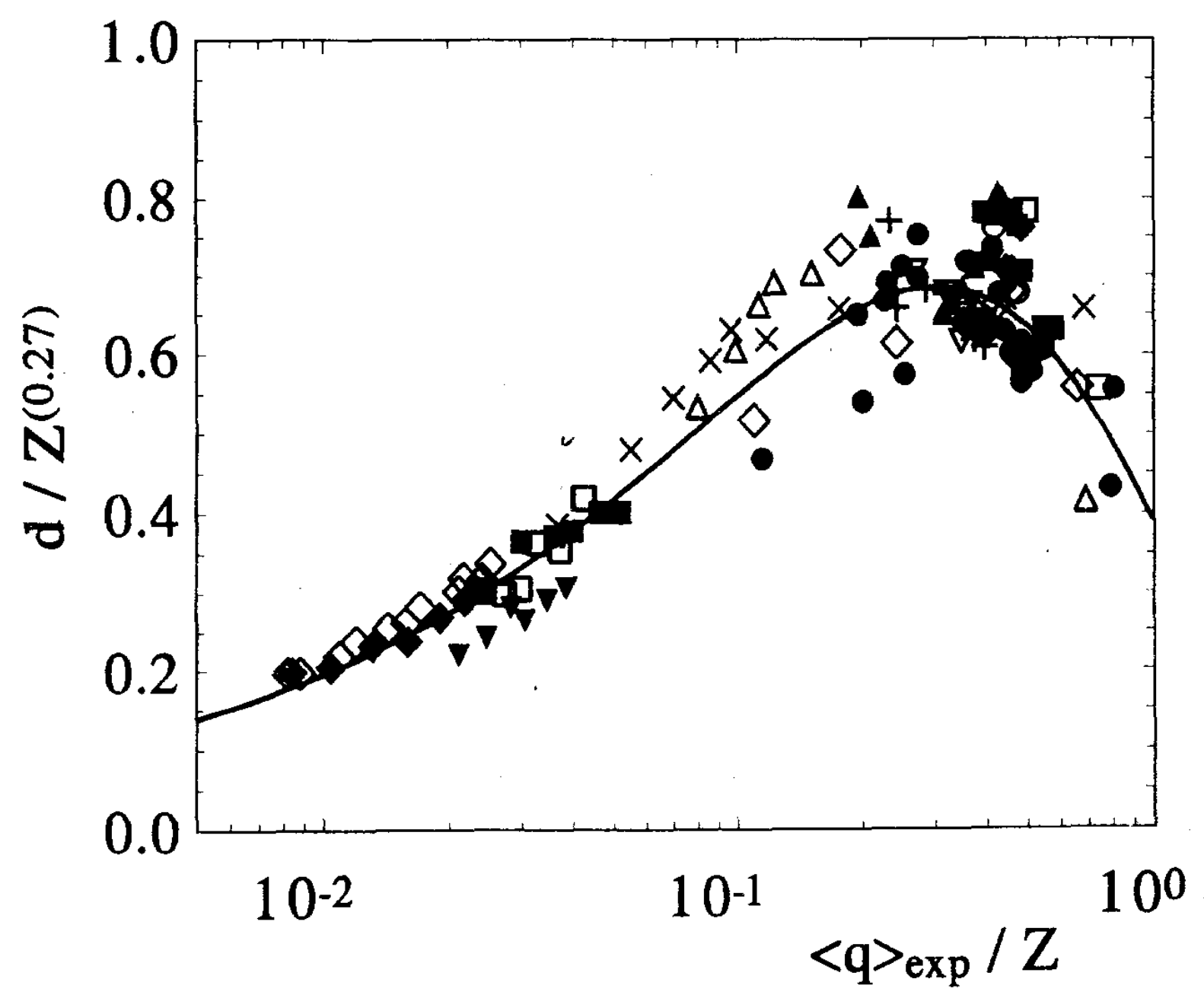

Fig.6. Systematics of the charge distribution width (symbols are the same as in fig.1). The solid line is the result of least-square fit using eq.(8) with constants in the text 
Table 2. Spline interpolated parameters $a(Z)$ and $b(Z)$ in eq. (3). Linear extrapolation is used for $Z>92$

\begin{tabular}{cccccc}
\hline$Z$ & $a(Z)$ & $b(Z)$ & $Z$ & $a(Z)$ & $b(Z)$ \\
\hline 53 & 1.0000 & 0.0000 & 82 & 1.2847 & 0.1605 \\
54 & 1.0156 & $9.640 \times 10^{-3}$ & 83 & 1.2889 & 0.1625 \\
55 & 1.0308 & $1.909 \times 10^{-2}$ & 84 & 1.2899 & 0.1629 \\
56 & 1.0455 & $2.814 \times 10^{-2}$ & 85 & 1.2881 & 0.1619 \\
57 & 1.0592 & $3.661 \times 10^{-2}$ & 86 & 1.2839 & 0.1598 \\
58 & 1.0718 & $4.430 \times 10^{-2}$ & 87 & 1.2775 & 0.1566 \\
59 & 1.0829 & $5.101 \times 10^{-2}$ & 88 & 1.2693 & 0.1525 \\
60 & 1.0921 & $5.653 \times 10^{-2}$ & 89 & 1.2597 & 0.1477 \\
61 & 1.0989 & $6.052 \times 10^{-2}$ & 90 & 1.2491 & 0.1424 \\
62 & 1.1025 & $6.264 \times 10^{-2}$ & 91 & 1.2377 & 0.1368 \\
63 & 1.1024 & $6.253 \times 10^{-2}$ & 92 & 1.2260 & 0.1310 \\
64 & 1.0979 & $5.984 \times 10^{-2}$ & 93 & 1.2142 & 0.1251 \\
65 & 1.0888 & $5.456 \times 10^{-2}$ & 94 & 1.2025 & 0.1193 \\
66 & 1.0776 & $4.803 \times 10^{-2}$ & 95 & 1.1907 & 0.1134 \\
67 & 1.0671 & $4.193 \times 10^{-2}$ & 96 & 1.1789 & 0.1076 \\
68 & 1.0603 & $3.795 \times 10^{-2}$ & 97 & 1.1672 & 0.1017 \\
69 & 1.0599 & $3.777 \times 10^{-2}$ & 98 & 1.1554 & $9.591 \times 10^{-2}$ \\
70 & 1.0691 & $4.308 \times 10^{-2}$ & 99 & 1.1436 & $9.006 \times 10^{-2}$ \\
71 & 1.0906 & $5.554 \times 10^{-2}$ & 100 & 1.1318 & $8.422 \times 10^{-2}$ \\
72 & 1.1260 & $7.596 \times 10^{-2}$ & 101 & 1.1201 & $7.838 \times 10^{-2}$ \\
73 & 1.1716 & 0.1015 & 102 & 1.1083 & $7.254 \times 10^{-2}$ \\
74 & 1.2223 & 0.1286 & 103 & 1.0965 & $6.670 \times 10^{-2}$ \\
75 & 1.2729 & 0.1547 & 104 & 1.0848 & $6.085 \times 10^{-2}$ \\
76 & 1.3178 & 0.1773 & 105 & 1.0730 & $5.501 \times 10^{-2}$ \\
77 & 1.3518 & 0.1940 & 106 & 1.0612 & $4.917 \times 10^{-2}$ \\
78 & 1.3695 & 0.2025 & 107 & 1.0495 & $4.333 \times 10^{-2}$ \\
79 & 1.3656 & 0.2003 & 108 & 1.0377 & $3.749 \times 10^{-2}$ \\
80 & 1.3346 & 0.1850 & 109 & 1.0259 & $3.165 \times 10^{-2}$ \\
81 & 1.2892 & 0.1628 & 110 & 1.0141 & $2.580 \times 10^{-2}$ \\
\hline & & & & &
\end{tabular}

Fig.5 illustrates the data of fig. 1 (application of formula (1)) corrected with the function (7). A general agreement is achieved for the whole energy range. This agreement is within $\pm 6 \%$ for the spline interpolated $a(Z)$ and $b(Z)$ (fig.5b) and slightly worse for these parameters determined by the least-square approximation (fig.5a) at low energies. 
We obtained also a new systematics of the charge distribution width. Fig.6 displays the $y=d / Z^{0.27}$ values [15] plotted against $x=\langle q\rangle_{\text {exp }} / Z$ for the available data for $Z \geq 53$. We fitted a function of the form

$$
y=A x^{B} \exp (-C x)
$$

to the data, by the least-square method. The best values of the fitting constants were obtained:

$$
A=2.10176, B=0.510987 \text {, and } C=1.68505 \text {. }
$$
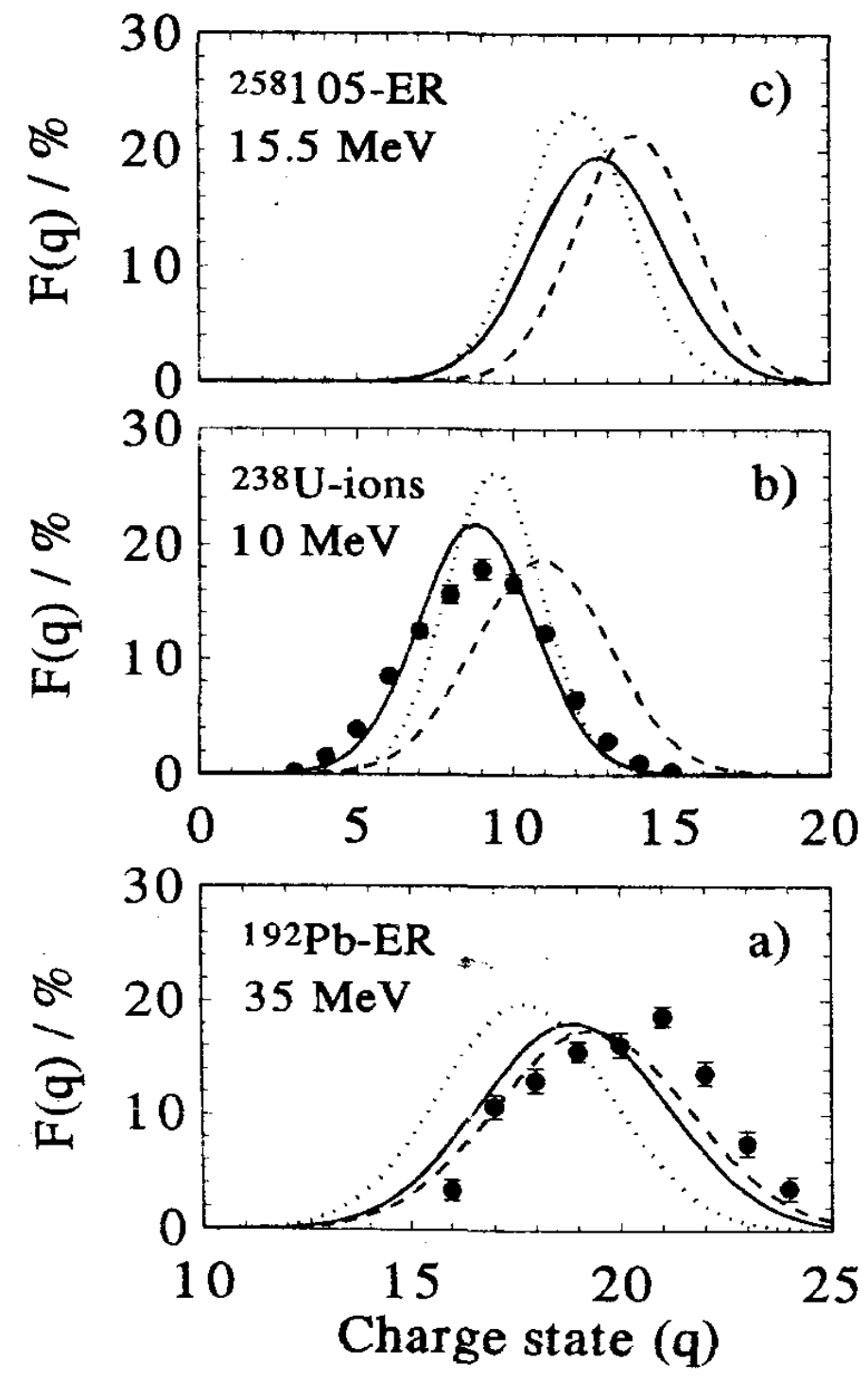

Fig.7. Some examples of the ionic charge distribution. Experimental data [2, 16] are shown as filled circles, our predictions using eqs.(1)-(8) are shown with solid lines, calculations by Nikolaev and Dmitriev [3] are shown with dotted lines and calculations by Shima et al. [4, 15] are shown with dashed lines 
The presented systematics of the mean charges and the charge distribution widths were used to predict ICD for some heavy ions and ER. The predicted distributions are shown in Fig.7 along with similar ones obtained from the other predictions $[3,4,15]$ and some experimental distributions for ER [2] and U-ions [16] passing through a carbon foil. The correction for $\langle q\rangle_{S I M}$ is small for the $\mathrm{Pb}$ ER. Because of this, the ICD is nearly the same as the predicted one given by the formula (1) [4] and width systematics [15]. Being necessary to obtain a good agreement with the experimental data [16], our correction is significant for heavier ions. Without this correction the predicted ICD $[3,4,15]$ deviate considerably from the experimental ones [16].

Present estimations of the ICD are used for the computer simulation of the ER's transportation through the electrostatic recoil separator VASSILISSA [6]. A good agreement was achieved between the calculated and experimental transportation efficiencies for the Po - Ac ER in the investigated energy region of $10-40 \mathrm{MeV}$ [17]. Carring out the experiments on synthesis of ${ }^{258} 105$ in the reaction ${ }^{27} \mathrm{Al}\left({ }^{236} \mathrm{U}, 5 \mathrm{n}\right)[18]$, the showed ICD for the ${ }^{258} 105$ (fig.7c) was used for the optimization of the separator parameters.

\section{Acknowledgement}

The authors would like to thank Professor G.M. Ter-Akopian for his encouragement and suggestions in editing the manuscript.

\section{References}

[1] G. Münzenberg, in: Handbook of Nuclear Decay Methods, eds.: W.Greiner and D.N.Poenaru (CRC Press, in press); CiSl-92-76 (1992).

[2] N.K. Skobelev, V.Z. Maidikov and N.T. Surovitskaya, Z. Phys. A314 (1983) 5.

[3] V.S. Nikolaev and I.S. Dmitriev, Phys. Lett. A28 (1968) 277.

[4] K. Shima, T. Ishịhara and T. Mikumo. Nucl. Instr. and Meth. 200 (1982)605.

[5] G. Münzenberg, W. Faust, S. Hofmann, P. Armbruster, K. Cü̈tner and H. Ewald, Nucl. Instr. and Meth. 161 (1979) 65.

[6] A.V. Yeremin, A.N. Andreyev, D.D. Bogdanov, V.I. Chepigin, V.A. Gorshkov, A.I. Ivanenko, A.P. Kabachenko, L.A. Rubinskaya, E.M. Smirnova, S.V. Stepantsov, E.N. Voronkov and G.M. Ter-Akopian, Nucl. Instr. and Metb. A274 (1989) 528.

[7] W. Faust, G. Münzenberg, S. Hofmant, W. Reisdorf, K.-H. Sclimidt. P. Armbruster and K. Güttner, Nucl. Instr. and Meth. 166 (1979) 397. 
[8] H.W. Gäggeler, D.T.Jost, A. Türter, P. Armbruster, W. Brüchle, H. Folger, F.P. HeBberger, S. Hofmann. G. Münzenberg, V. Ninov, W. Reisdorf, M. Schädel, K. Sümmerer, J.V. Kratz, U. Scherer and M.E. Leino, Proc. Int. School-Seminar on Heavy Ion Physics, Dubna, 1989 (JINR D7-90-142, 1990) p 119.

[9] A.V. Yeremin, A.N. Andreyev, D.D. Bogdanov, A.P. Kabachenko, O.N. Malyshev, O.A.Orlova, G.M. Ter-Akopian and V.I. Chepigin, JINR E15-90-347, Dubna (1990).

[10] A.B. Wittkower and H.D. Betz, At. Data 5 (1973) 113.

[11] K. Shima, T. Mikumo and H. Tawara, At. Data Nucl. Data Tables 34 (1986) 357.

[12] K. Shima, N. Kuno, M. Yamanouchi and H. Tawara, At. Data Nucl. Data Tables $51(1992) 173$.

[13] E. Baron, M. Bajard and Ch. Ricaud, Nucl. Instr. and Meth. A328 (1993) 177.

[14] A.G. Popeko, R.N. Sagaidak and A.V. Yeremin, Proc. Int. School-Seminar on Heavy Ion Physics, Dubna, 1993 (JINR E7-93-274, Vol.II, 1993) in press.

[15] K. Shima, N. Kuno and M. Yamanouchi, Phys. Rev. A40 (1989) 3557.

[16] A.B. Wittkower and H.D. Betz, Phys. Rev. A7 (1973) 159.

[17] A.V. Yeremin, A.N. Andreyev, D.D. Bogdanov, V.I. Chepigin, M. Florek, F.P. HeBberger, S. Hofmann, A.P. Kabachenko, O.N. Malyshev, V. Ninov, Yu.Ts. Oganessian, A.G. Popeko, R.N. Sagaidak, S. Sharo, G.M. Ter-Akopian, M. Veselsky, Proc. Int. School-Seminar on Heavy Ion Physics, Dubna, 1993 (JINR E7-93-274, Vol.I) p.109.

[18] A.N. Andreyev, D.D. Bogdanov, V.I. Chepigin, A.P. Kabachenko, O.N. Malyshev, Yu.Ts. Oganessian, R.N. Sagaidak, G.M. Ter-Akopian, A.V. Yeremin, F.P. Heßberger, S. Hofmann, V. Ninov, M. Florek, S. Sharo, M. Veselsky, Z. Phys. A344 (1992) 225. 


\section{WILL YOU FILL BLANK SPACES IN YOUR LIBRARY?}

You can receive by post the books listed below. Prices - in US $\$$, including the packing and registered postage.

D13-85-793

$01,2-86-668$

D3,4,17-86-747

D9-87-105

D7-87-68

D2-87-123

D2-87-798

D14-87-799

D17-88-95

E1,2:88-426

D14-88-833

D13.88-938

Di7-88-681

D9-89-52

E2-89-525

D9-89-801

D19-90-457
Proceedings of the XII International Symposium on Nuclear Electronics, Dubna, 1985.

Proceedings of the VIUI International Seminar on High

23.00 Energy Physics Problems, Dubna, 1986 (2 volumes)

Proceedings of the $V$ International School on Neutron

Physics. Alushta, 1986.

Proceedings of the X All.Union Conference on Charged

25.00 Particle Accelerators. Dubna, 1986 (2 volumes)

Proceedings of the International School-Seminar on Heavy Ion Physics. Dubna, 1986.

Proceedings of the Conference "Renormalization Group-86". Dubna, 1986.

Proceedings of the VIII International Conference on the Problems of Quantum Field Theory. Alushta, 1987.

Proceedings of the International Symposium on Muon and Pion Interactions with Matter. Dubna, 1987.

Proceedings of the IV International Symposium on Selected Topics in Statistical Mechanics. Dubna, 1987. Varna, Bulgaria, 1987.

Proceedings of the International Workshop on Modern Trends in Activation Analysis in JNR. Dubna, 1988

Proceedings of the XIII International Symposium on Nuclear Electronics. Varna, 1988

Proceedings of the International Meeting 'Mechanisms of High-T $\mathrm{c}$ Superconductivity". Dubna, 1988.

Proceedings of the XI All-Union Conference on Charged Particle Accelerators. Dubna, 1988 (2 volumes)

Proceedings of the Seminar 'Physics of $\mathrm{e}^{+} \mathrm{e}^{-}$-Interactions". Dubna, 1988.

Proceedings of the Intemational School-Seminar on Heavy Ion Physics. Dubna, 1989. 
E17-90-472

Proceedings of the International Seminar

D13-90-479

Proceedings of the International Workshop 'Solid State Nuclear Track Detectors and Their Applications"

Orders for the above-mentioned books can be sent at the address: 
Сагайдак Р.Н., Еремин А.В.

О зарядовых распределениях остатков испарения, прошедших через углеродную фольгу

Анализировались параметры зарядовых распределений, такие как средняя величина и ширина, для тяжелых $(Z \geq 53)$ ионов, прошедших углеродные фольги, с точки зрения применимости известных эмпирических систематик. Значительные отклонения (до 60\%) для средних величин зарядов, измеренных экспериментально, от аналогичных, вычисленных с помощью эмпирических формул, получены для ионов с $E \leq 0,1 \mathrm{MэB/a.е.м.}$ Предложены поправки к формуле Шимы и др., обеспечивающие общее согласие с экспериментальными данными в пределах $\pm 6 \%$ для всей области исследованных энергий ионов $0,001 \leq E \leq 10 \mathrm{MэB/a.е.м.} \mathrm{Предложена} \mathrm{так-}$ же новая систематика для ширин зарядовых распределений. Полученные систематики использовались для ионно-оптических расчетов транспортировки ядер-остатков испарения через электростатический сепаратор ядер отдачи ВАСИЛИСА.

Работа выполнена в Лаборатории ядерных реакций ОИЯИ.

Препринт Объединенного института ядерных исследований. Дубна, 1993

Sagaidak R.N., Yeremin A.V.

On Ionic Charge Distributions of Heavy Evaporation

Residues Passing Through a Carbon Foil

Parameters of the ionic charge distributions, i.e. mean charge values and charge distribution widths, for very heavy $(Z \geq 53$ ) ions passing through a carbon foil were analyzed from the view point of applicability of known empirical systematics. Strong deviations (up to $60 \%$ ) for experimental mean charge values were obtained from those deduced from empirical formulae at energies of ions less than $0.1 \mathrm{MeV} / \mathrm{amu}$. Corrections providing a general agreement with the experimental data within of $\pm 6 \%$ at the energies of ions $0.001 \leq E \leq$ $\leq 10 \mathrm{MeV} /$ amu to the formula of Shima et al. are proposed. New systematics of the widths for charge distributions is also presented. The obtained systematics were used in ion-optical calculations of transportation of evaporation residues through the electrostatic recoil separator VASSILISSA.

The investigation has been performed at the Laboratory of Nuclear Reactions, JINR.

Preprint of the Joint Institute for Nuclear Research. Dubna, 1993 
$15 \mathrm{p}$.

Редактор Е.И.Хижняк. Макет Р.Д.Фоминой

Подписано в печать 14.10 .93

Формат 60х90/16. Офсетная печать. Уч.-изд. листов 1,09

Тираж 315. Заказ 46735

Издательский отдел Объединенного института ядерных исследований

Дубна Московской области 